\title{
Implementation of the RRC-KI Neutron Flux Correction Methodology in the RELAP5-3D Code
}

\author{
J. E. Fisher
}

August 2003

Idaho National Engineering and Environmental Laboratory Bechtel BWXT Idaho, LLC 


\title{
Implementation of the RRC-KI Neutron Flux Correction Methodology in the RELAP5-3D Code
}

\author{
James E. Fisher
}

August 2003

Idaho National Engineering and Environmental Laboratory Idaho Falls, Idaho 83415

Prepared for the

International Atomic Energy Agency and for the

U.S. Department of Energy

Under DOE Idaho Operations Office

Contract DE-AC07-99ID13727 


\section{Contents}

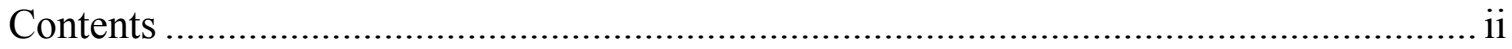

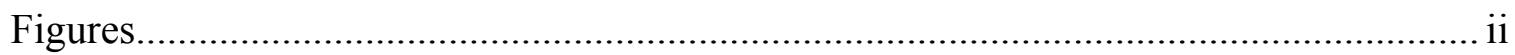

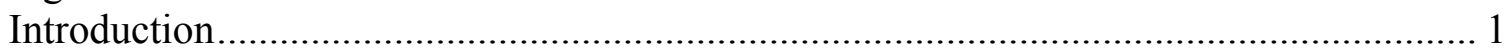

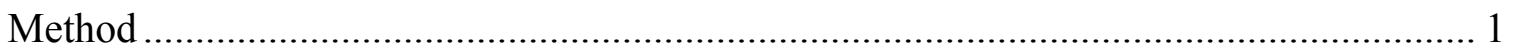

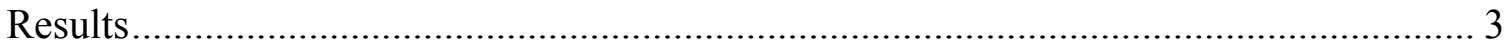

Correction Methodology Applied to 1999 Version of Kursk-1 ...................................... 3

Correction Methodology Applied to New Version of Kursk-1 ................................... 4

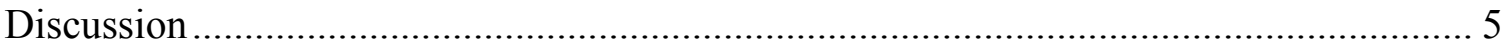

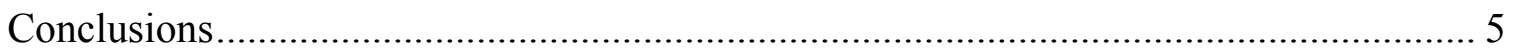

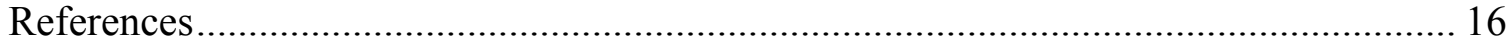

\section{Figures}

Figure 1. Kursk-1 Reactor Load. .......................................................................... 7

Figure 2. Axial Power Profile using Nu-Sigf Correction Method.................................. 8

Figure 3. Radial Power Profile at $X=42$ using Nu-Sigf Correction Method. ................... 8

Figure 4. Radial Power Profile at $Y=41$ using Nu-Sigf Correction Method. .................... 9

Figure 5. Radial Power Profile at $X=10$ using Nu-Sigf Correction Method. ................... 9

Figure 6. Radial Power Profile at $Y=67$ using Nu-Sigf Correction Method. .................. 10

Figure 7. Axial Power Profile using Burnup Correction Method................................... 10

Figure 8. Radial Power Profile at $\mathrm{X}=42$ using Burnup Correction Method.................... 11

Figure 9. Radial Power Profile at $Y=41$ using Burnup Correction Method. ................... 11

Figure 10. Radial Power Profile at $X=10$ using Burnup Correction Method................. 12

Figure 11. Radial Power Profile at $Y=67$ using Burnup Correction Method. ................. 13

Figure 12. Axial Power Profile in $3200 \mathrm{MW}$ Core using Nu-Sigf Correction. ............... 13

Figure 13. Radial Power Profile at $X=42$ in 3200 MW core using Nu-Sigf Correction

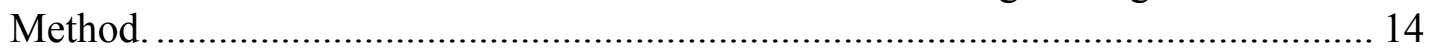

Figure 14. Radial Power Profile at $Y=41$ in 3200 MW core using Nu-Sigf Correction

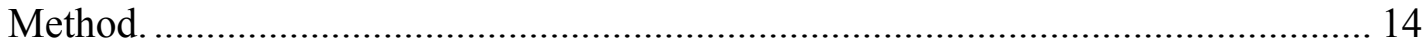

Figure 15. Radial Power Profile at $\mathrm{X}=10$ in $3200 \mathrm{MW}$ core using Nu-Sigf Correction

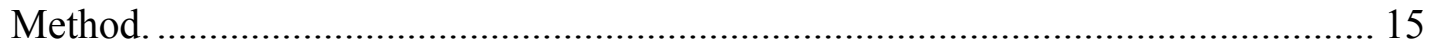

Figure 16. Radial Power Profile at $Y=67$ in $3200 \mathrm{MW}$ core using Nu-Sigf Correction

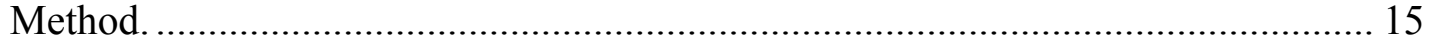




\section{Implementation of the RRC-KI Neutron Flux Correction Methodology in the RELAP5-3D Code}

\section{Introduction}

The International Atomic Energy Agency has sponsored a program, "Accident Analysis and its Associated Training Programme for RBMK-1000 Kursk-1 NPP (Phase II)". Under the auspices of this program, Reactor Research Centre "Kurchatov Institute" (RRC-KI) has implemented a Neutron Flux Correction Methodology in Version 1.2.2 of the RELAP5-3D code. The implementation was done on the RINSC workstation in Moscow, and is documented in Reference 1. Because access to the RELAP5-3D source coding by RRC-KI was limited to only the subroutines needed for the interface to the flux correction subroutine, the implementation was done using local variable arrays. The input detector data were accessed by the subroutine via local data files, residing on the computer disc storage. INEEL was then tasked with providing a permanent installation in the current release of the code. Therefore, the subject of this report is implementation of the Neutron Flux Correction Methodology in RELAP5-3D Version 2.0.3 as a permanent feature.

\section{Method}

The neutron flux correction algorithm, as described in Reference 1, involves addition of a local error term, applied to either the neutron generation cross-section, i.e. $v \cdot \Sigma_{\mathrm{f}}$, or to the burnup, in a specific region of the core by comparing the local thermal neutron flux calculated for the region to the readings of in-core detectors. The following discussion is based on the methodology description in Reference 1.

The radial in-core detectors (ICD-R) provide a measured value for the fuel assembly (FA) power at a particular radial position. The axial in-core detectors (ICD-A) provide axial distribution of neutron fluxes in several channels. Each kinetics node within each FA is associated with its nearest ICD-R and ICD-A detector within the core. A matrix of correction (DS) values is therefore calculated, one for each kinetics node in the core:

$\mathrm{DS}=\mathrm{DS}_{\mathrm{R}}+\mathrm{DS}_{\mathrm{A}}+\mathrm{DS}_{\mathrm{cef}}$

where

DS is the total additive correction term

$\mathrm{DS}_{\mathrm{R}}$ is the radial component of flux correction

$\mathrm{DS}_{\mathrm{A}}$ is the axial component, and

$\mathrm{DS}_{\mathrm{cef}}$ is the eigenvalue correction.

These terms are defined as follows: 


$$
\begin{aligned}
& D S_{R}=-\varepsilon_{1} \cdot \frac{\Phi_{R}-\Phi_{M}}{\Phi_{M}} \\
& D S_{A}=-\varepsilon_{1} \cdot \frac{\Phi_{R}^{Z}-\Phi_{M}^{Z}}{\Phi_{M}^{Z}} \\
& D S_{c e f}=-\varepsilon_{2} \cdot \frac{K_{e f f}-1}{K_{e f f}}
\end{aligned}
$$

where

$\Phi_{\mathrm{R}}$ is the total thermal neutron flux, in the calculational mesh, at radial position $\mathrm{R}$

$\Phi_{M}$ is the value of the thermal neutron flux, measured by the ICD-R detector

$\Phi^{Z}{ }_{R}$ is the thermal neutron flux at the level $\mathrm{Z}$, in the calculational mesh

$\Phi^{\mathrm{Z}}{ }_{\mathrm{M}}$ is the value of the thermal neutron flux, at the level $\mathrm{Z}$, measured by the ICD-A detector.

$\varepsilon_{1}$ is an empirical coefficient, with the value $0.5 \times 10^{-4}$ when the correction is applied to $v \cdot \Sigma_{\mathrm{f}}$ and -66.86 when the correction is applied to burnup.

$\varepsilon_{2}$ is an empirical coefficient, with the value $4 \times 10^{-3}$ when the correction is applied to $v \cdot \Sigma_{\mathrm{f}}$ and -5348.84 when applied to burnup.

Further, the corrections are limited to $4 \%$ of $v \cdot \Sigma_{\mathrm{f}}$, or $10 \%$ of burnup, to avoid large changes of cross-section or burnup, which can arise from "doubtful" detector readings.

The mechanics of implementation of the neutron flux correction methodology into Version 2.0.3 of the code were performed by INEEL. All the control parameters and the detector data input were moved to the RELAP5-3D input file, and the coding was written to process this information. The data storage for the correction values was moved to main storage array for RELAP5, which is written to the restart-plot file. Output features were added to write the correction factors to a new file "fluxdata", which is intended to be read and processed by a spreadsheet program. Also, features were added to the input processor so the correction values, from a steady-state initialization run, can be included in the input file to supply the correction values for the transient version of the input file. 


\section{Results}

Following the implementation of the neutron flux correction methodology into Version 2.0.3 of RELAP5-3D, the results of calculations, using the Kursk-1 input file, were compared to those results calculated using Version 1.2.2 with the modifications added by RRC-KI. The numbers produced by Version 2.0 .3 were identical with those produced by Version 1.2.2, with one stipulation regarding calculation of the xenon flux correction factor. In Version 1.2.2, the reference power value used for this correction included prompt and decay power from fission. This has been corrected in Version 2.0.3 so that only the prompt power is used. Using the Version 1.2.2 coding in Version 2.0.3 is required to obtain exact agreement of the neutron flux correction procedure. The results of calculations that used the neutron flux correction methodology are described in the following paragraphs.

\section{Correction Methodology Applied to 1999 Version of Kursk-1}

The neutron flux correction methodology was applied to the RELAP5-3D input file of the Kursk-1 NPP ${ }^{2}$, and the corrected power profiles were compared to plant data. Results of calculations with both $v \cdot \Sigma_{\mathrm{f}}$-based and burnup-based corrections were compared. Steadystate initialization calculations were made for a period of $20 \mathrm{~s}$. The correction values were then entered into the transient input file, and one time step of the transient simulation was performed. Comparisons were made to the Kursk-1 power distribution values for the initial values (at $\mathrm{t}=0 \mathrm{~s}$ ), the final initialization values (at $\mathrm{t}=20 \mathrm{~s}$ ), and for the initial value for the transient simulation with the corrected values in the input file (TR at $\mathrm{t}=0 \mathrm{~s}$ ). Figure 1 shows a plan view of the Kursk-1 NPP, and indicates the XY numbering scheme for the FA map. This figure will be referenced in the comparison results. North is taken to be at the top of Figure 1, the X positions proceed from West to East and the Y positions proceed from South to North.

Figure 2 shows the axial power profile comparison for the correction calculation using the $v \cdot \Sigma_{\mathrm{f}}$-based correction. In the uncorrected axial power profile, the shape was reasonable, but the peak occurred higher in the core, and the magnitude of the axial power was underpredicted in the upper region of the core. As shown, both the corrected value ( $\mathrm{t}=20 \mathrm{~s})$ and the initial transient value with the correction in the input file (TR $\mathrm{t}=0$ ) showed much closer agreement with the data.

Figure 3 is a comparison of the radial power shape for a typical region along a NorthSouth plane passing near the center of the core ( $\mathrm{Y}$ distribution at position $\mathrm{X}=42$ of Figure 1). In this plane, the uncorrected values were higher than the measured values in the North region, and generally lower than the measured values in the South. As shown, the corrected values and the initial transient values showed better general agreement with the data. 
Figure 4 shows a comparison of the radial power along an East-West plane passing near the center of the core (X distribution at $\mathrm{Y}=41$ of Figure 1). In this plane, the uncorrected values were generally lower than the data. Again, the correction was shown to improve the agreement between the code and the data.

Figure 5 shows a comparison of the radial power along the West edge of the core $(X=10)$. In this plane, comparison between the initial $(t=0)$ and the corrected $(t=20)$ calculated values, indicates that the correction did not have a large effect on the power profile. However, the power profile for the initial conditions of the transient (TR $t=0)$ showed a closer match to the data.

The final comparison for the correction calculation using $v \cdot \Sigma_{\mathrm{f}}$ is shown in Figure 6 , and is for the radial power profile along the North edge of the core at $Y=67$. In this plane, the uncorrected calculation was significantly higher than the data. The correction showed improvement in the agreement between the calculation and the data in this plane as well.

Figures 7 through 11 are the equivalent comparisons of the axial and radial power shapes for the calculations using the burnup-based correction. Figure 7 is the comparison of the axial power profile, and Figures $8,9,10$, and 11 are for radial planes at $X=42, Y=41$, $X=10$, and $Y=67$. These comparisons are the same as the ones shown for the calculations using $v \cdot \Sigma_{\mathrm{f}}$-based correction. The results were nearly identical to those obtained using the $v \cdot \Sigma_{\mathrm{f}}$-based correction.

\section{Correction Methodology Applied to New Version of Kursk-1}

Further comparisons were made for application of the neutron flux correction methodology to the most recent reference state of the Kursk-1 NPP. In this configuration, the core has a new fuel loading, a different burnup pattern, and is to be operated at $100 \%$ of design power (i.e. $3200 \mathrm{MW}$ ). For this comparison only the $v \cdot \Sigma_{\mathrm{f}^{-}}$ based correction method was used. RRC-KI has indicated that, because of the low burnup associated with this core, the burnup-based correction should not be used. In fact, the burnup-based flux correction method caused failure when it was used with this core. The steady-state initialization calculation appeared to run normally, and produced an array of burnup correction values. However, with these correction values and the updated power profile entered into the input file, the subsequent transient calculation failed to run, because the initial flux state of the neutron kinetics did not converge with the burnup-based corrections. It should be noted that the causes of code failures associated with the initial attempts to use the burnup-based correction method were identified and corrected.

Results of the comparison are in Figures 12 (axial power profile) and Figures 13, 14, 15, and 16 for the radial planes at $X=42, Y=41, X=10$, and $Y=67$. For this core configuration, there was apparent disagreement between the power profile and the corrected values in the radial profiles. Therefore, the actual radial detector data were included on the comparison plots along with the power profile data. The results show 
that in some cases, the detector radial data were not closely matched to the core power distribution data. For example, on Figure 13 (which shows the North-South plane at $X=42$ ), the corrected power profile followed the detector profile more closely than the power profile data, except for the southern-most region. The same observations can be made for the East-West plane at $Y=41$, in Figure 14, except for the region near the center of the core, and for the radial plane along the North edge at $Y=67$, in Figure 16. For the radial plane along the West edge at $X=10$, the corrected data, the power profile data, and the detector measurements were all in agreement.

\section{Discussion}

As noted, there is a limitation associated with burnup-based correction factors in low burnup cores. The user should be aware that application of burnup-based correction factors under these conditions will cause a code input processing failure, one which may not produce an error message, and therefore one which may be difficult to diagnose.

It is possible to generate $v \cdot \Sigma_{\mathrm{f}}$-based or burnup-based correction data that fails input checking in RELAP5. A detailed discussion is provided, because this issue has the potential to cause user problems. Within the $56 \times 56$ array that is used to specify the nodal data for the input file (i.e. zone figures, composition figures, nodal power data, and user variables), the positions on the periphery of the array do not represent active mesh locations. This is done to save storage space, and reduces the storage requirement from 3136 to 2188 . Numbers are required in the input file to fill the non-active positions, for ease of input formatting and readability. The placeholder value must be different from any valid value so the code input processor can determine the locations of the active positions. The code counts the active positions in the composition figure array, and compares this value to the number of active positions it locates in each of the other nodal data arrays. If it gets the wrong value, it issues the error message:

'0******** Incorrect number of legal entries'

For the integer arrays, " 0 " is used for the non-active, or "placeholder" positions, because the active positions always have non-zero, integer values. For the real arrays, however, the value " 0.0 " is a valid entry, and represents a non-fuel position, for example, in the nodal power data. The default for this "placeholder" number is -1.0 , although it can be specified to be a different value (see Word 17 of Card 30000000). The problem is that -1.0 is a possible value for either a $v \cdot \Sigma_{\mathrm{f}}$-based or a burnup-based correction, which are entered into the "user variable" nodal data. An alternative to using -1.0 for the placeholder is to use a very small real number, for example $1.0 \mathrm{e}^{-20}$ for active, non-fuel positions in the nodal power data, and to use 0.0 for the placeholder.

\section{Conclusions}

As shown by the results of comparing RELAP5-3D-calculated power profiles with the power profile data from Reference 2 , both the $v \cdot \Sigma_{\mathrm{f}}$-based and the burnup-based neutron flux correction methods improved the calculated power shapes. In the most recent core 
loading, operated at $3200 \mathrm{MW}$, the $v \cdot \Sigma_{\mathrm{f}}$-based correction method also resulted in a power profile that more closely matched the plant data. A limitation identified associated with the use of the burnup-based correction is that it is not applicable to low burnup core loading. 
NORTH
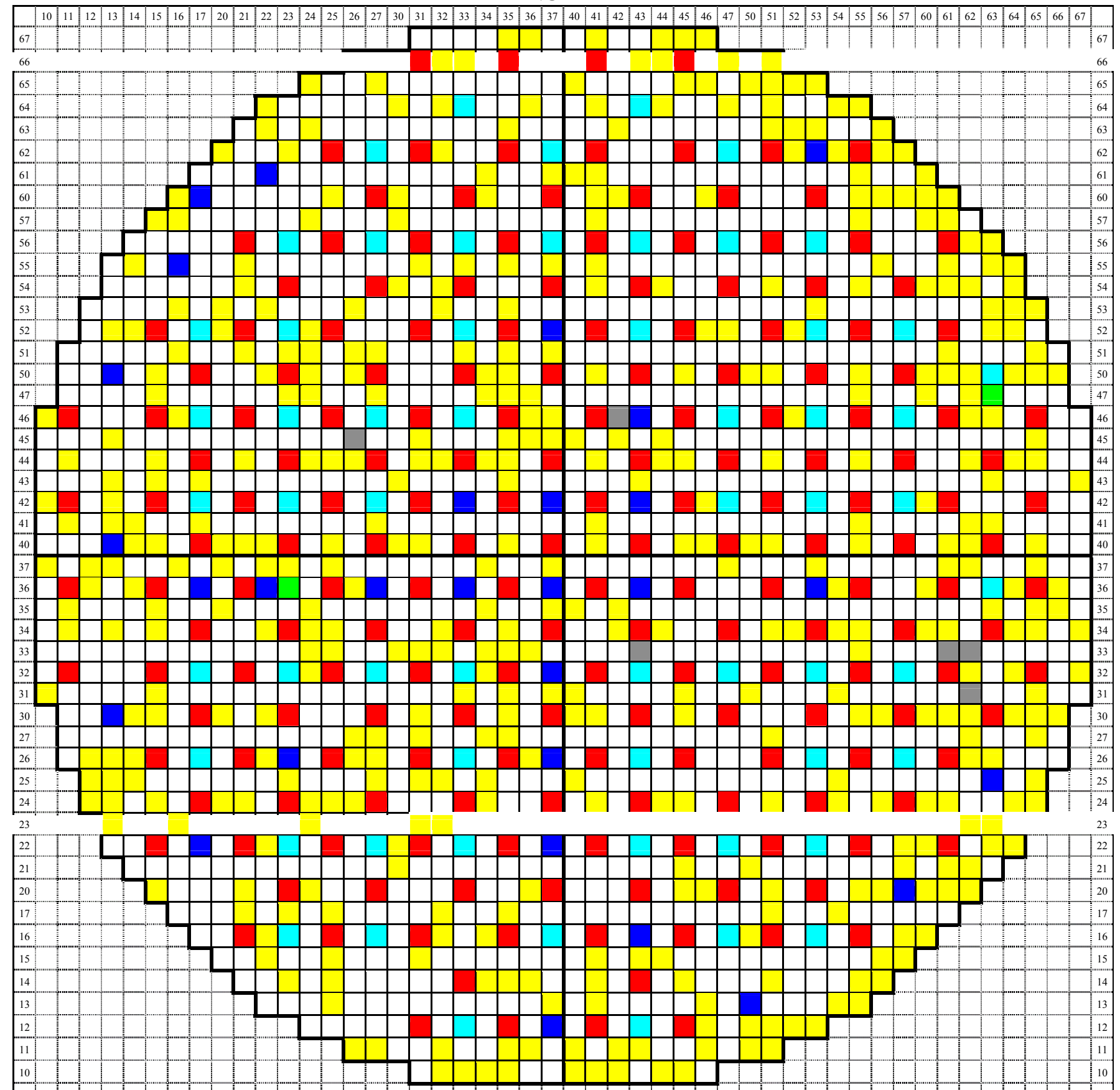

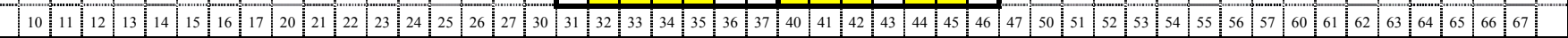

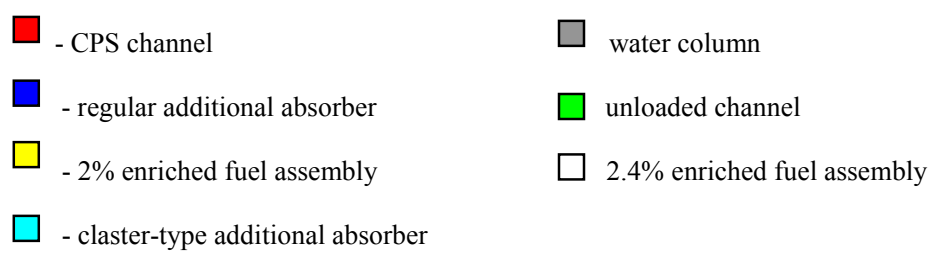

Figure 1. Kursk-1 Reactor Load. 


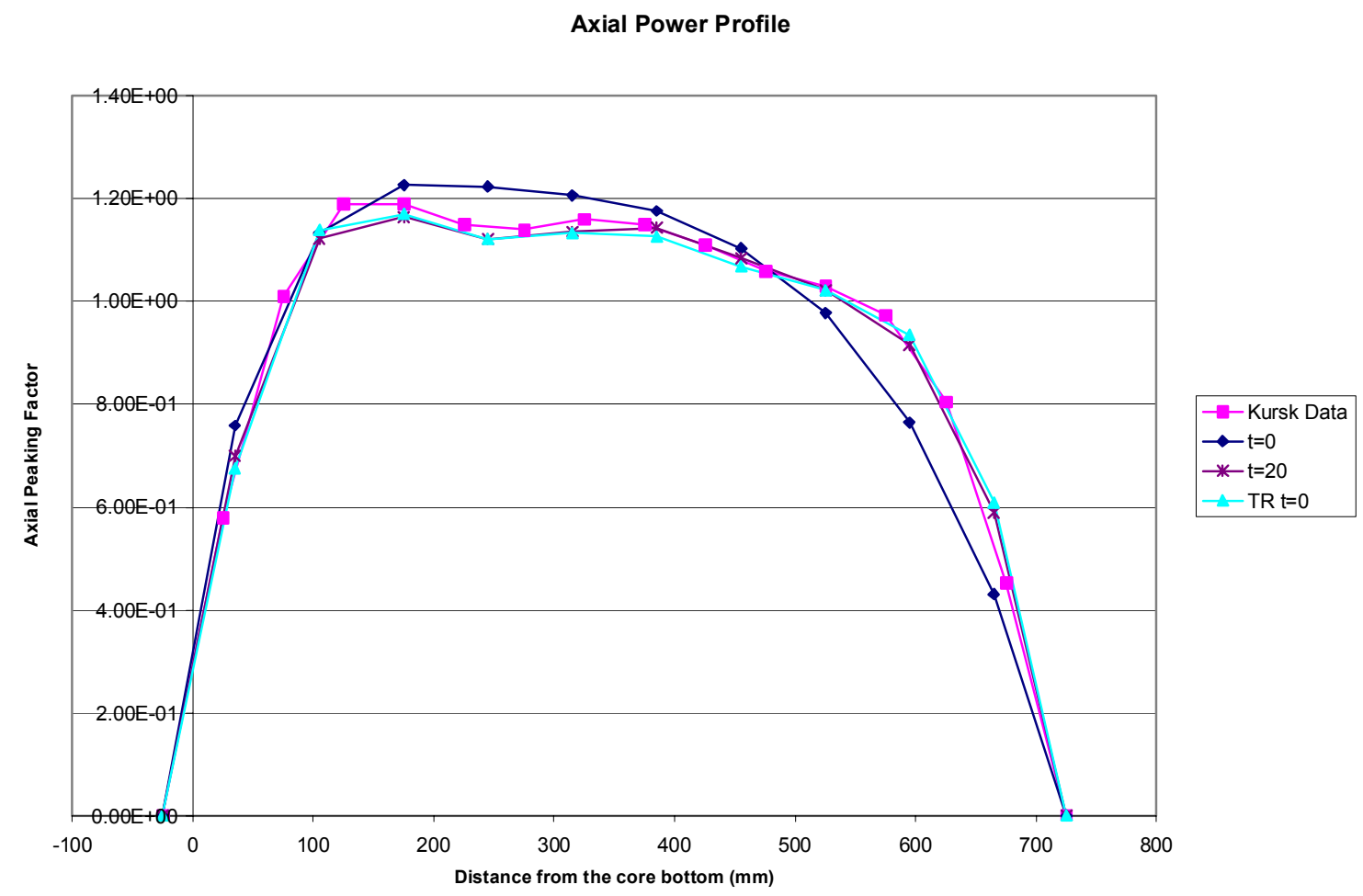

Figure 2. Axial Power Profile using Nu-Sigf Correction Method.

$X=42$

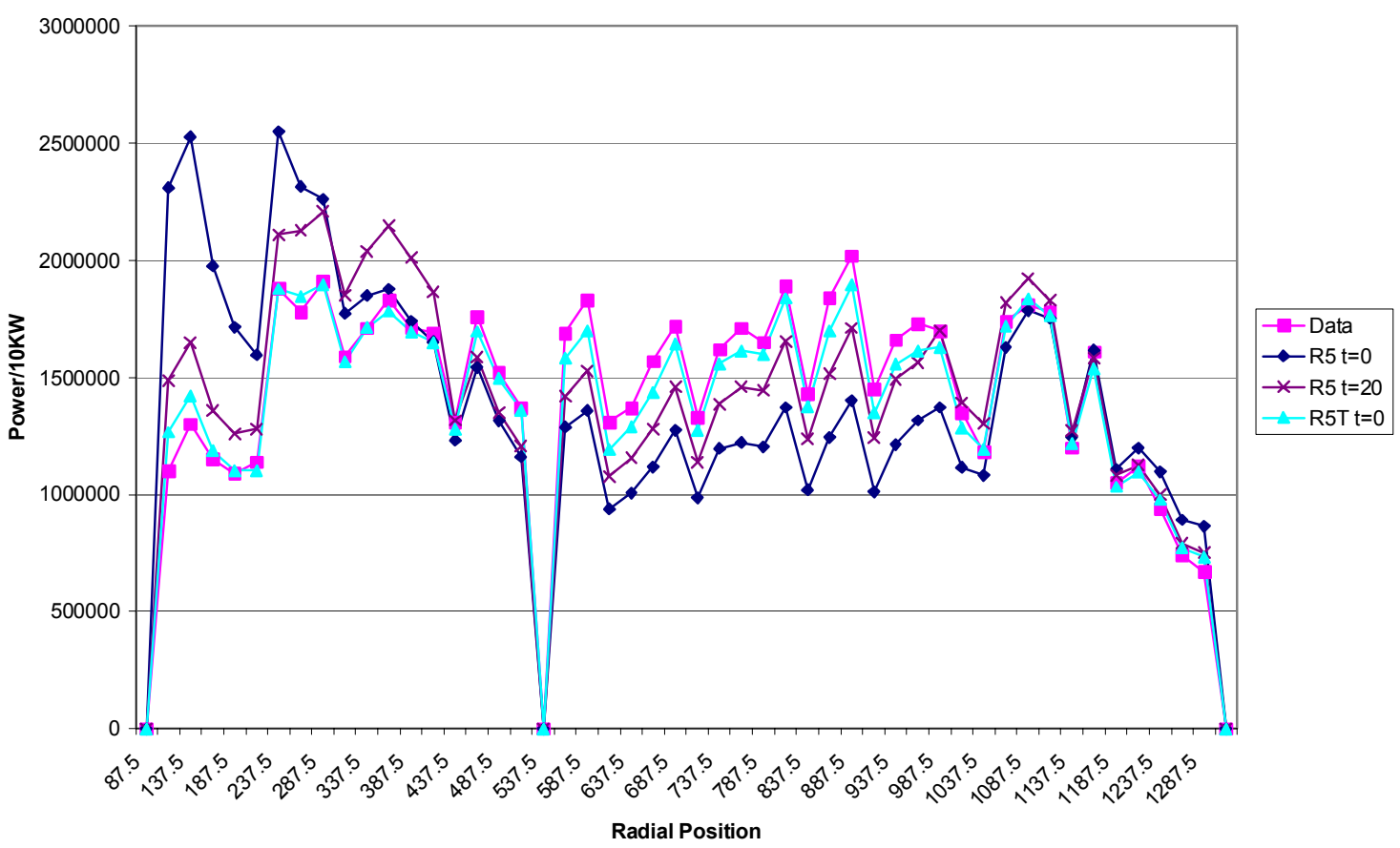

Figure 3. Radial Power Profile at $\mathrm{X}=42$ using Nu-Sigf Correction Method. 


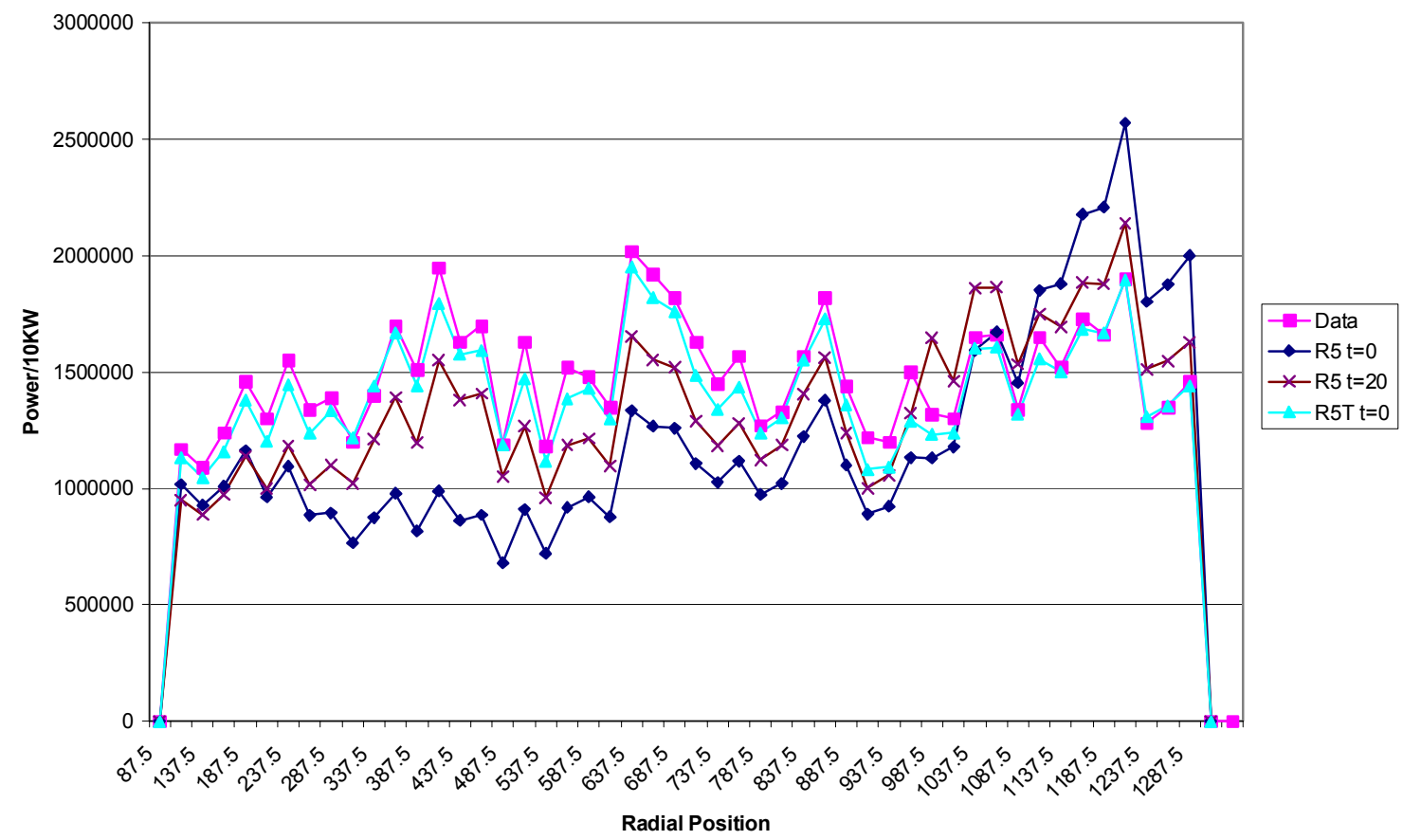

Figure 4. Radial Power Profile at $\mathrm{Y}=41$ using Nu-Sigf Correction Method.

$x=10$

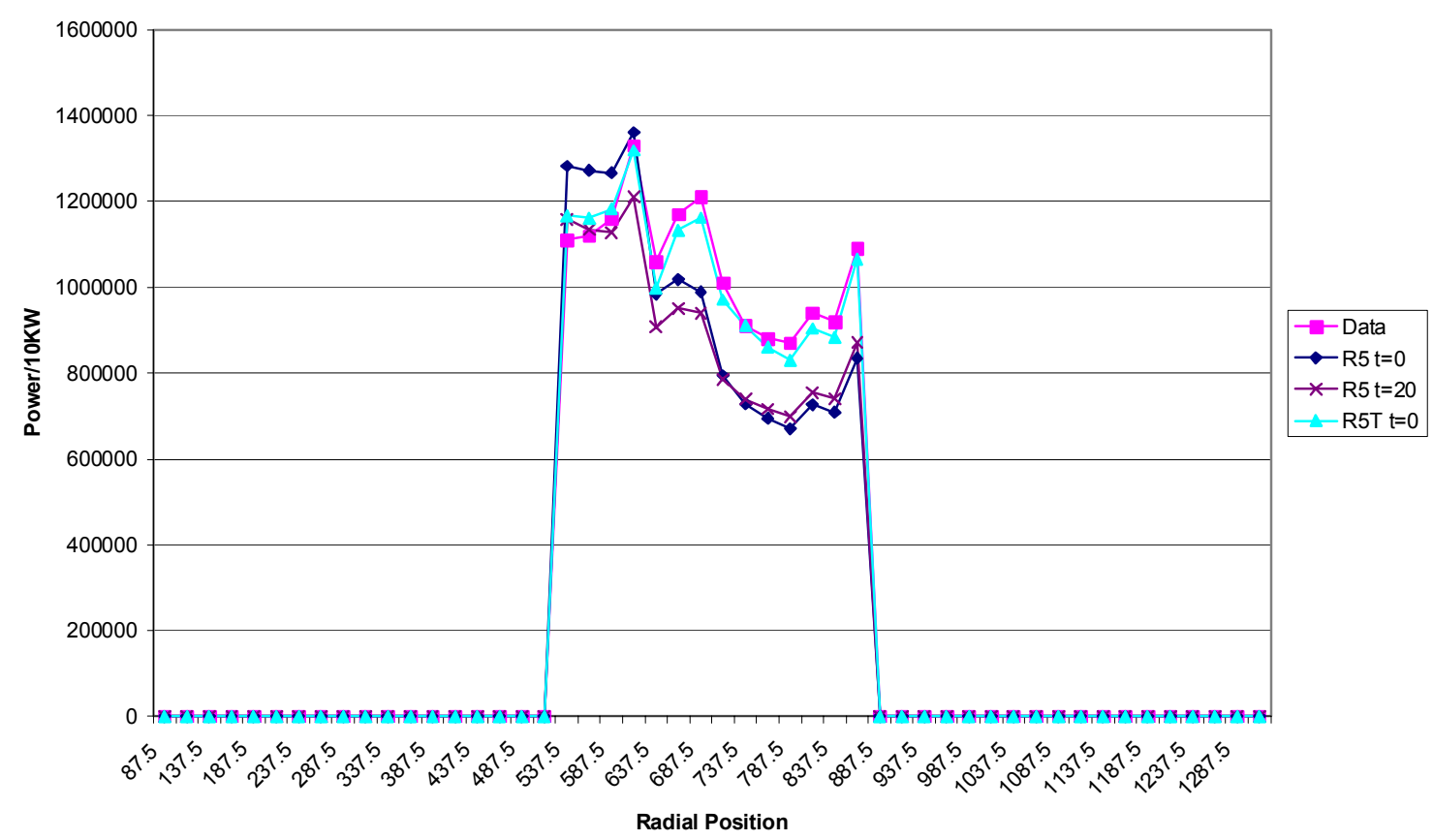

Figure 5. Radial Power Profile at $\mathrm{X}=10$ using Nu-Sigf Correction Method. 


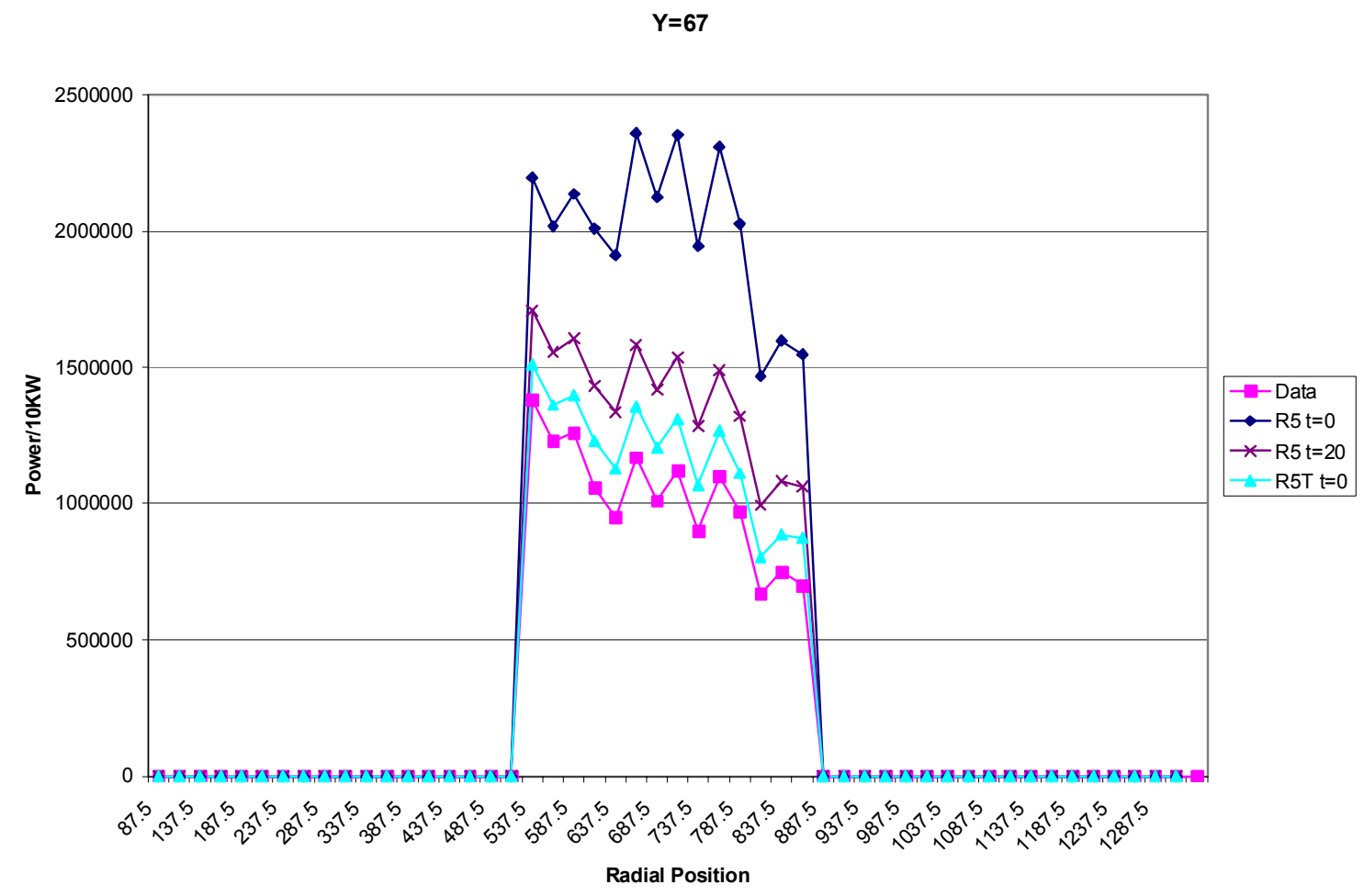

Figure 6. Radial Power Profile at $\mathrm{Y}=67$ using Nu-Sigf Correction Method.

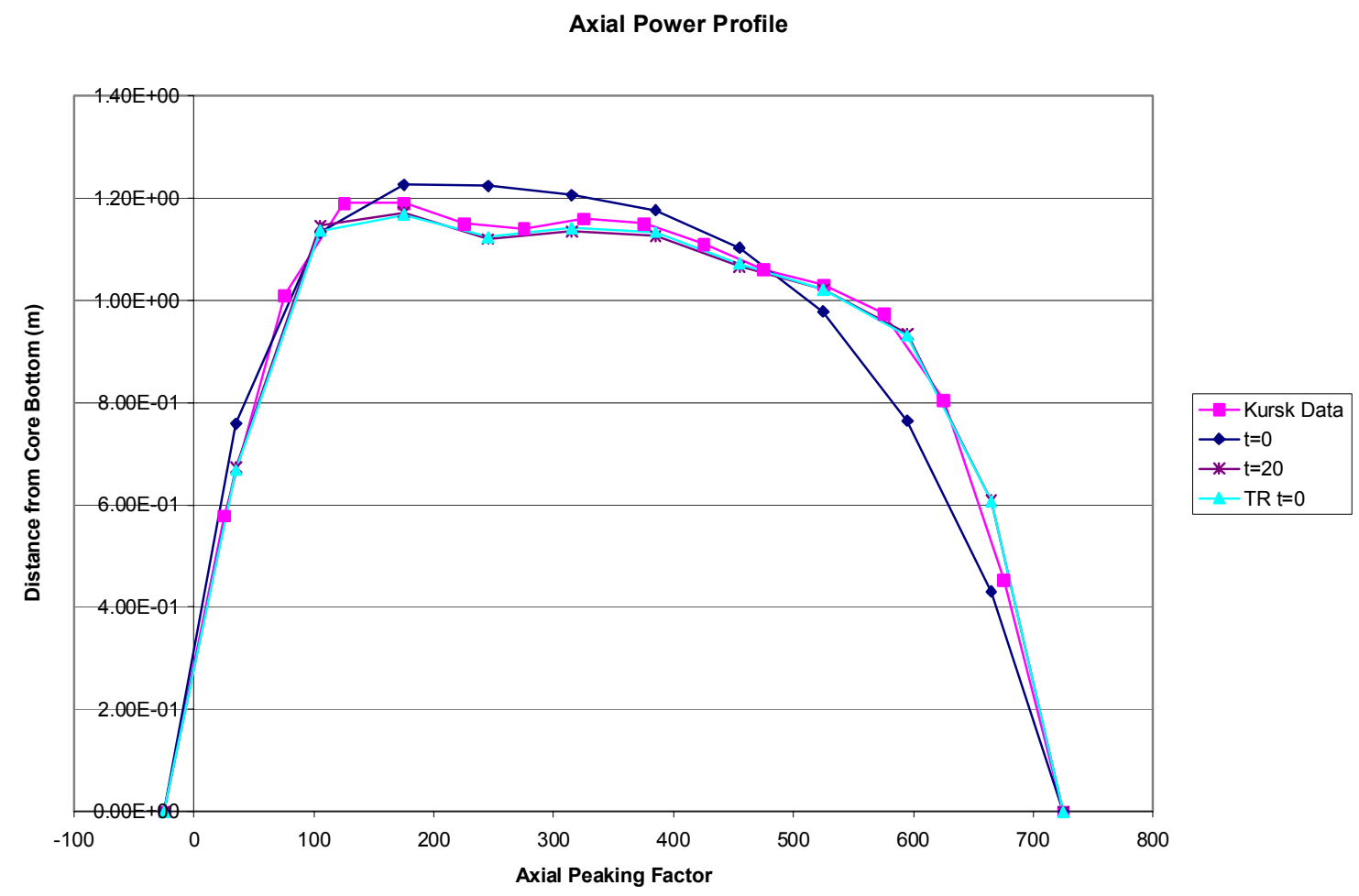

Figure 7. Axial Power Profile using Burnup Correction Method. 


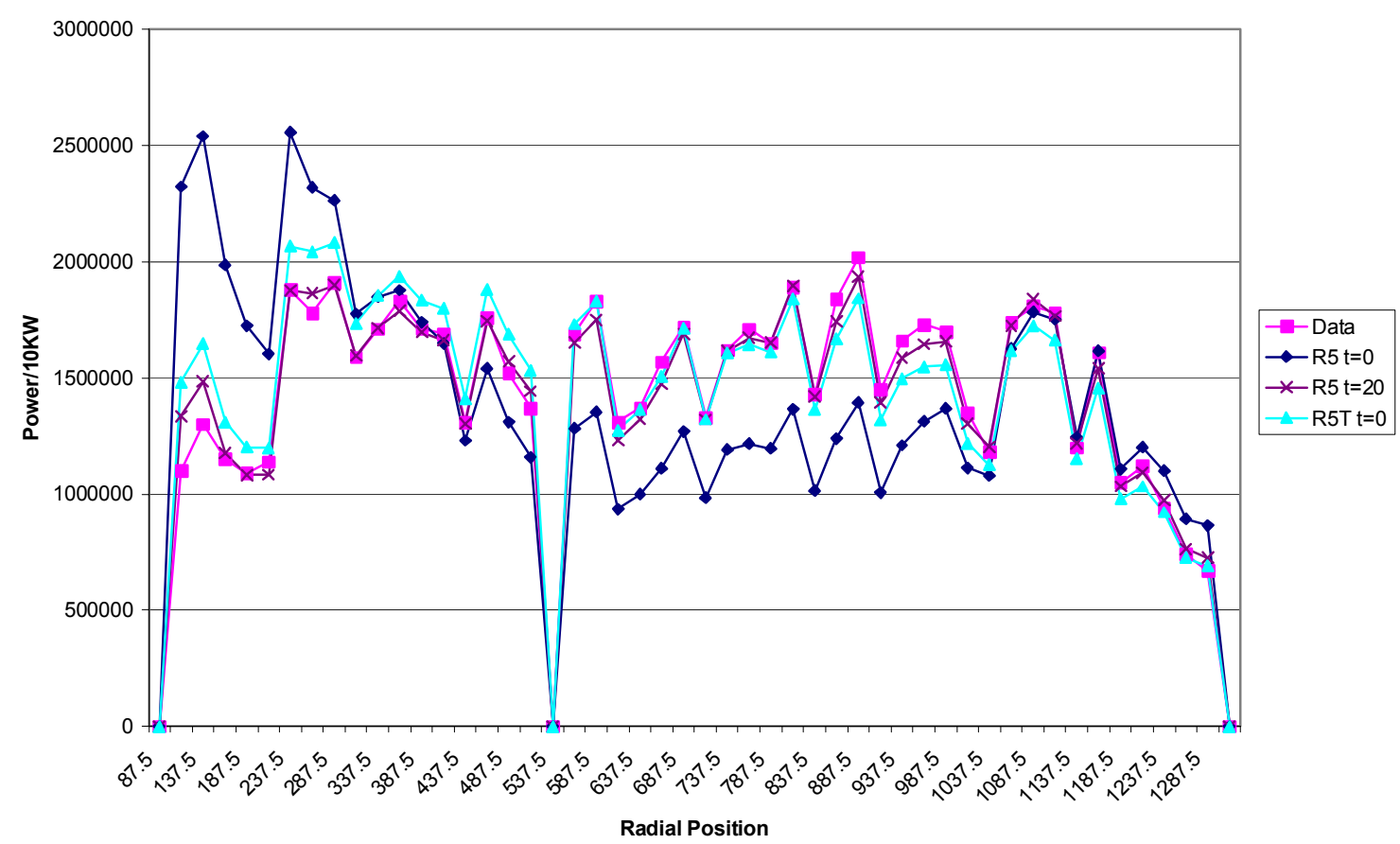

Figure 8. Radial Power Profile at $\mathrm{X}=42$ using Burnup Correction Method.

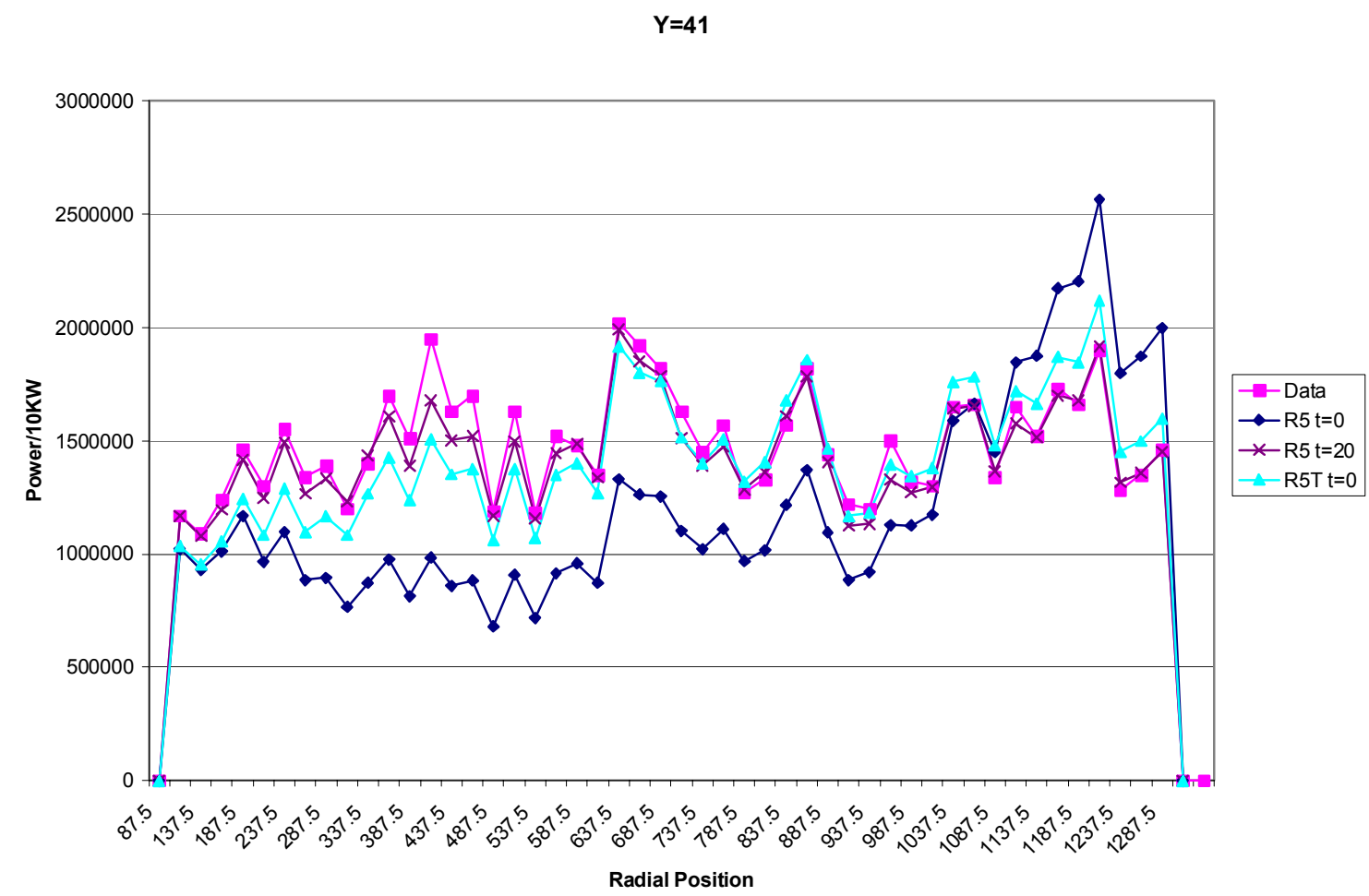

Figure 9. Radial Power Profile at $\mathrm{Y}=41$ using Burnup Correction Method. 


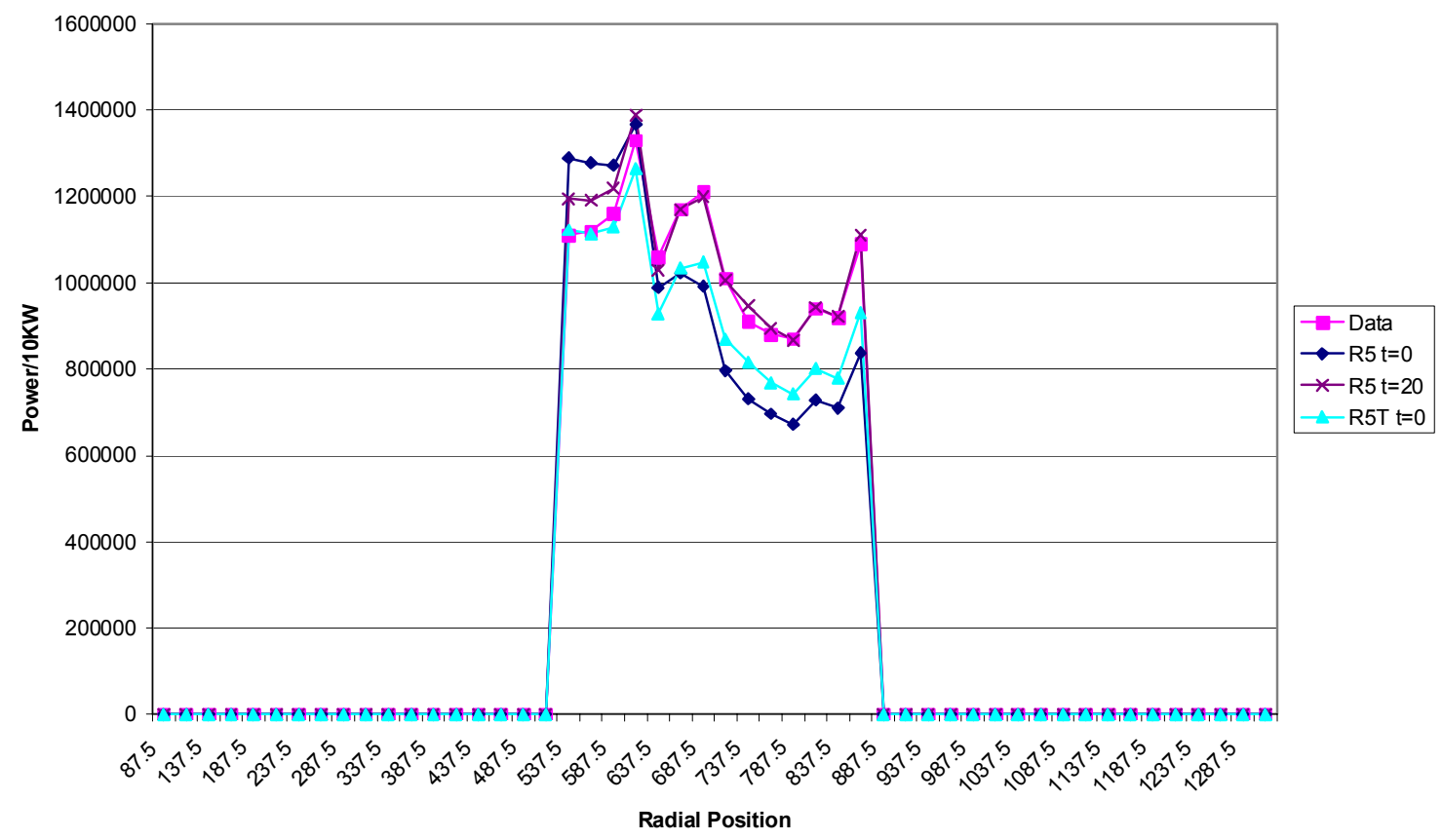

Figure 10. Radial Power Profile at $X=10$ using Burnup Correction Method.

$Y=67$

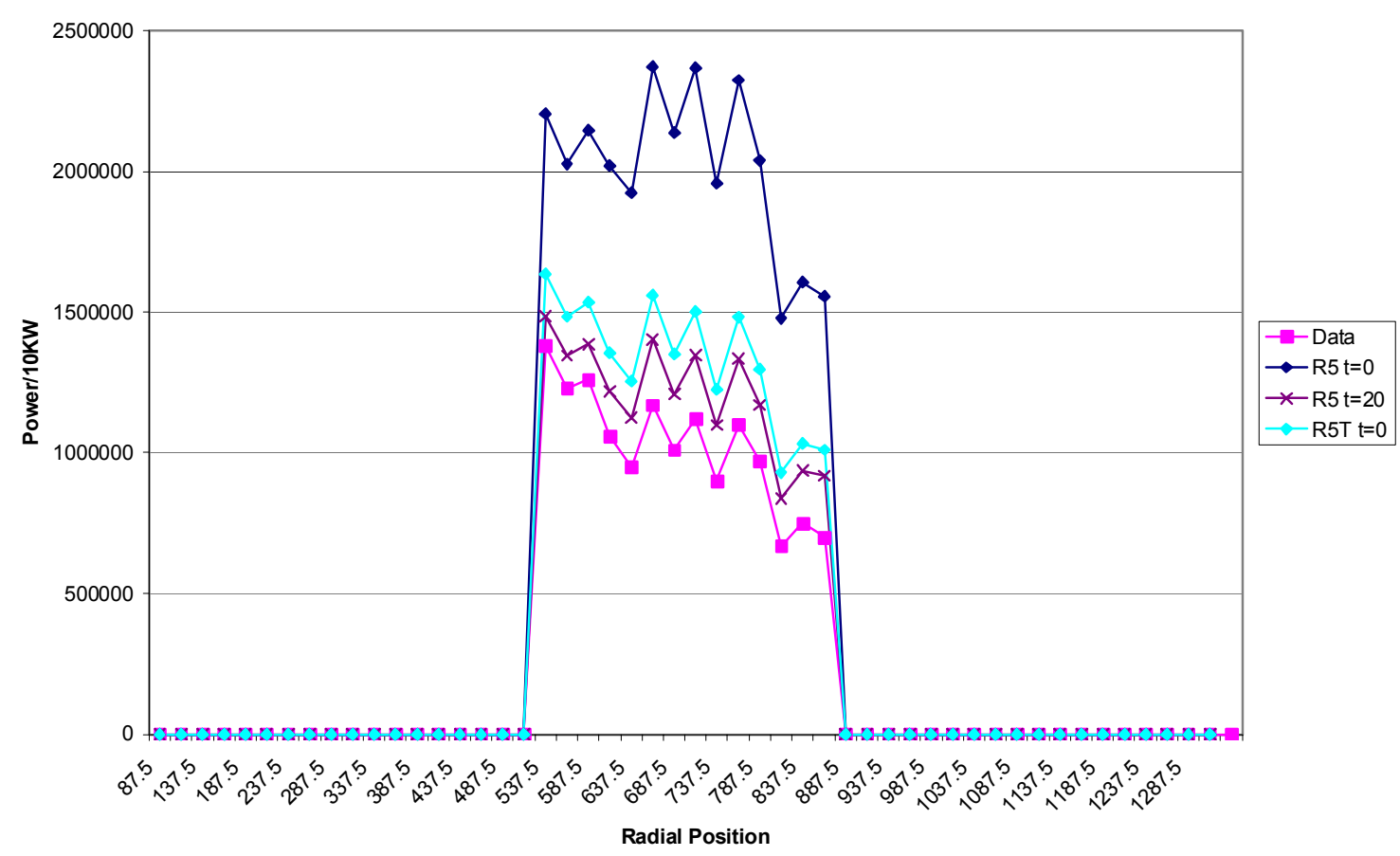


Figure 11. Radial Power Profile at $\mathrm{Y}=67$ using Burnup Correction Method.

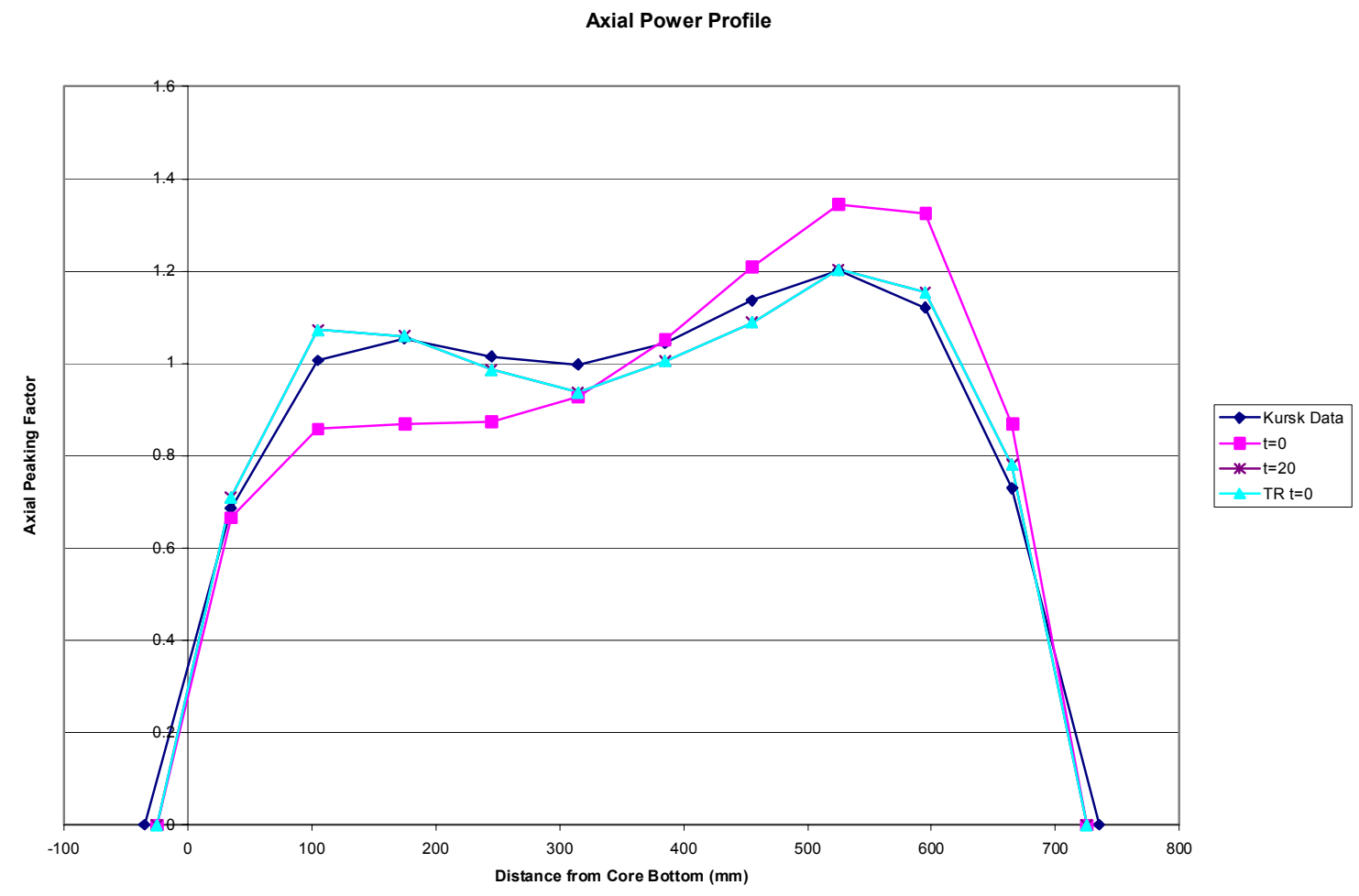

Figure 12. Axial Power Profile in 3200 MW Core using Nu-Sigf Correction.

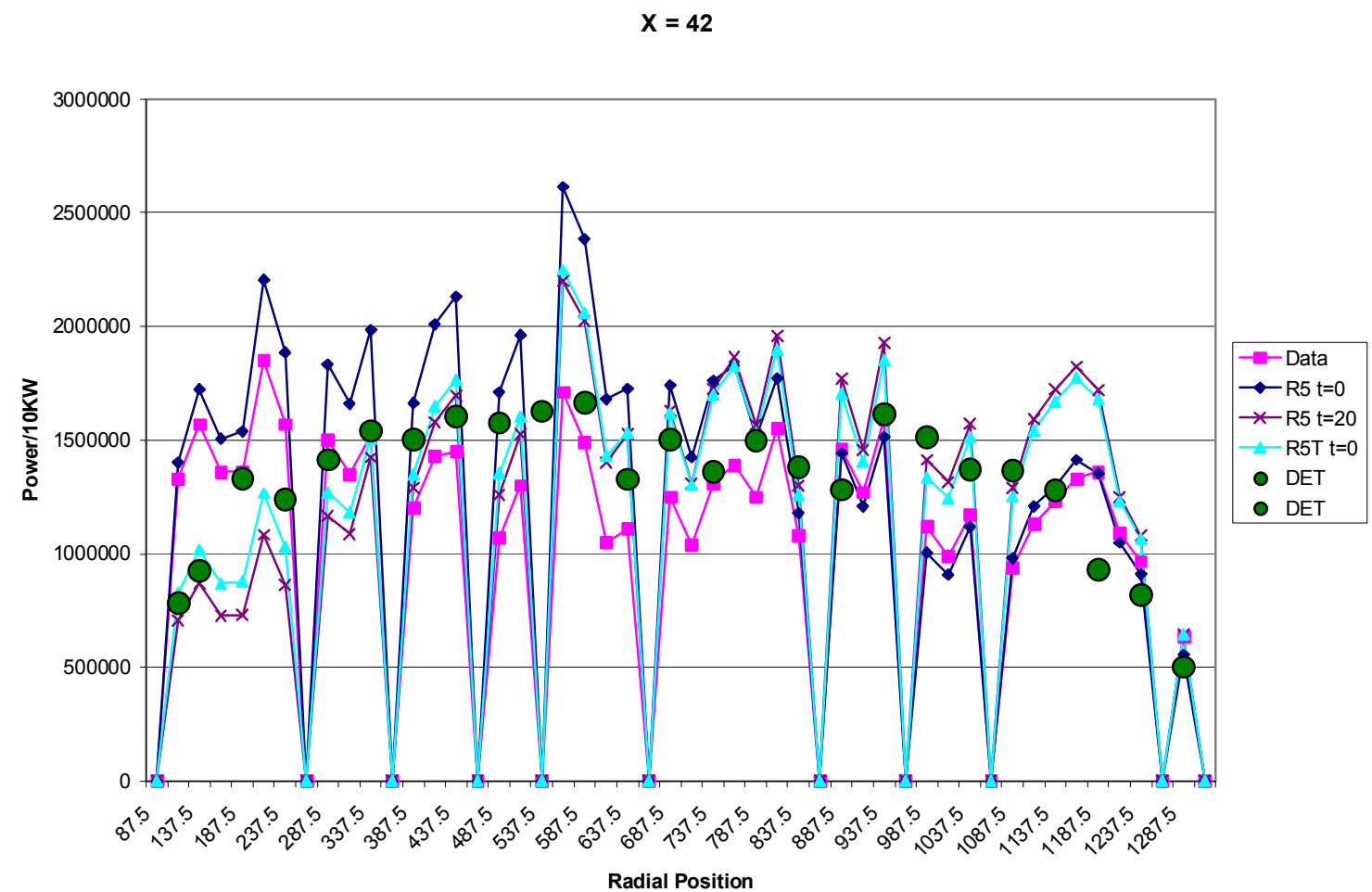


Figure 13. Radial Power Profile at $X=42$ in 3200 MW core using Nu-Sigf Correction Method.

$\mathrm{Y}=41$

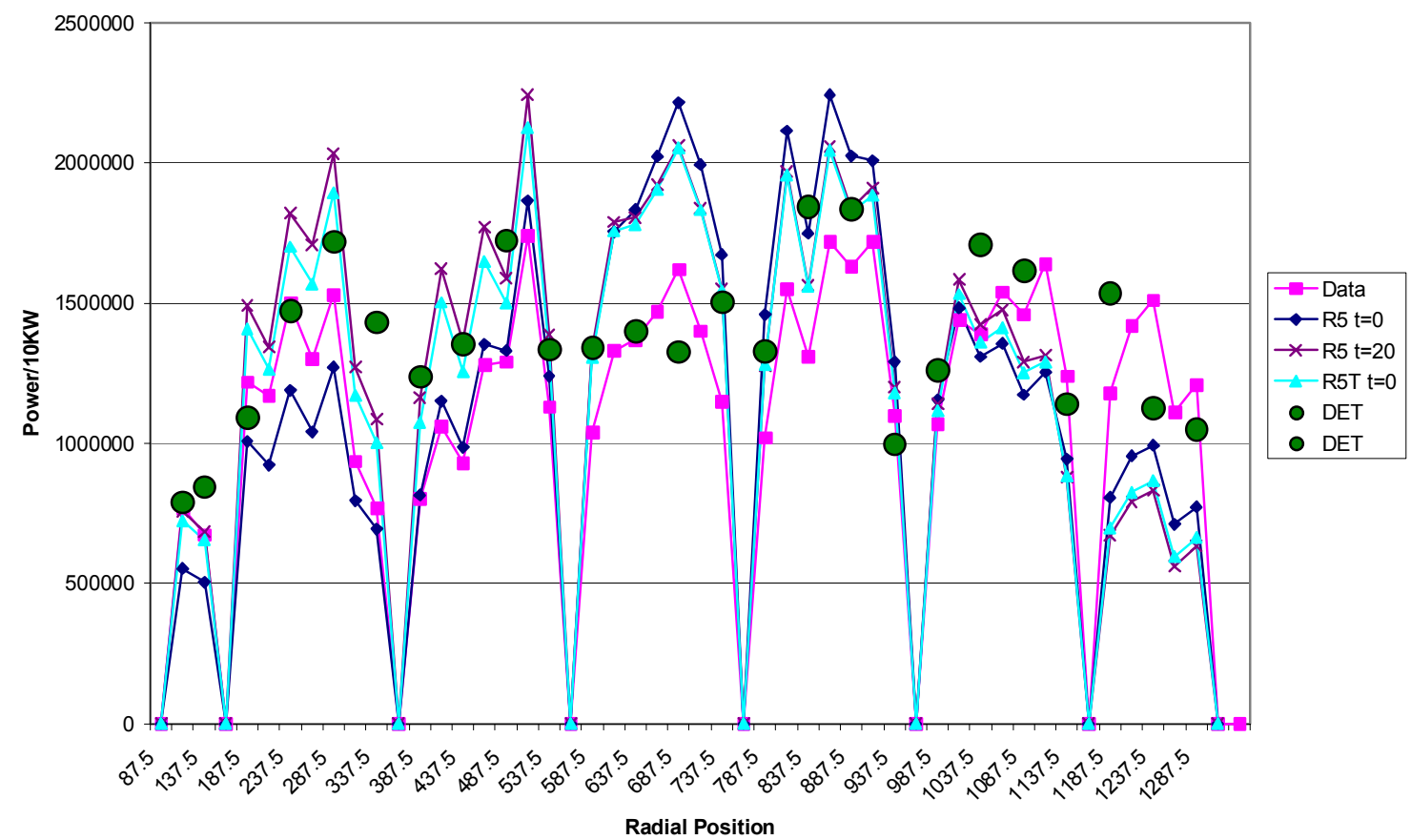

Figure 14. Radial Power Profile at $Y=41$ in 3200 MW core using Nu-Sigf Correction Method.

$X=10$

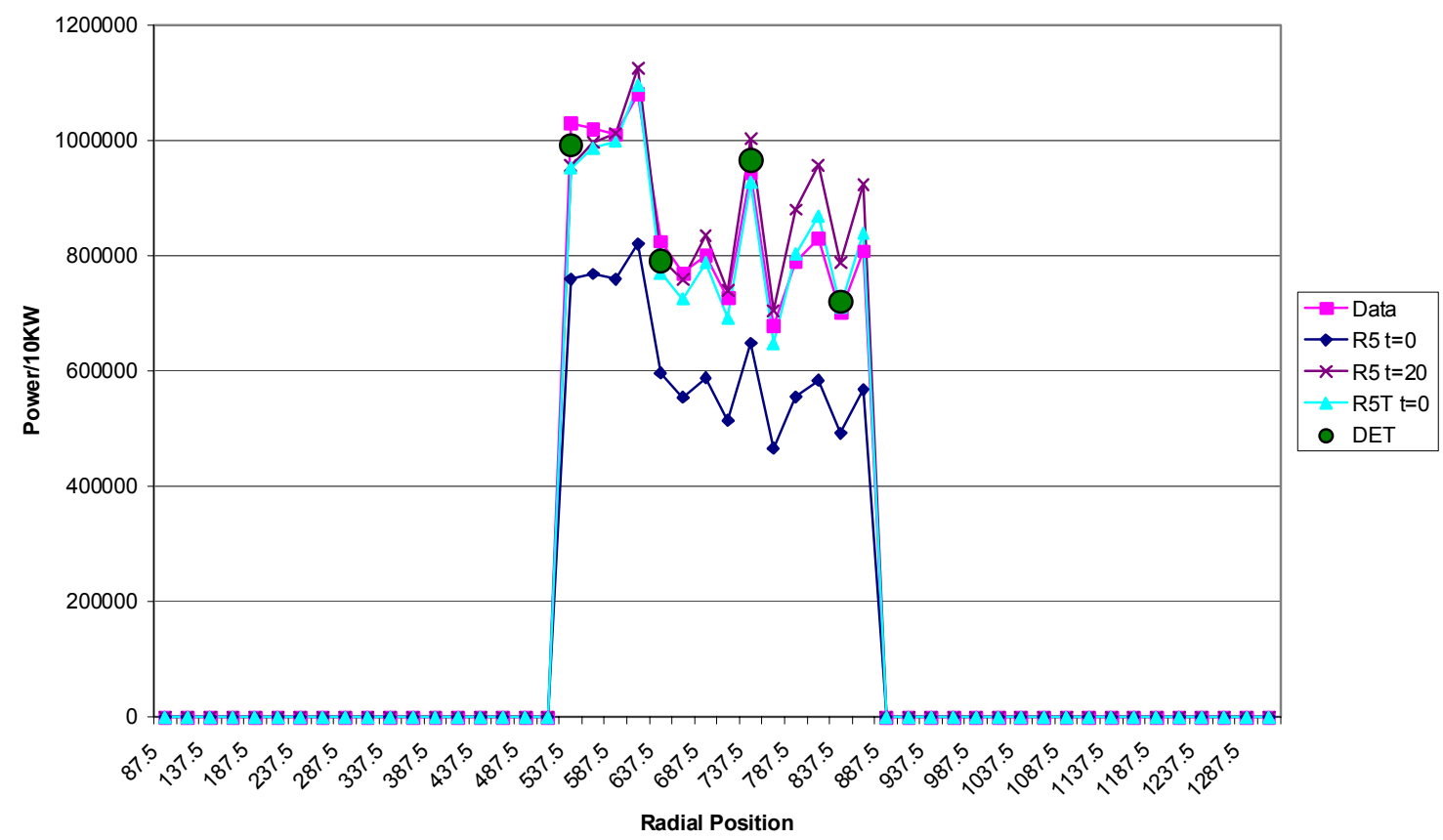


Figure 15. Radial Power Profile at $X=10$ in 3200 MW core using Nu-Sigf Correction Method.

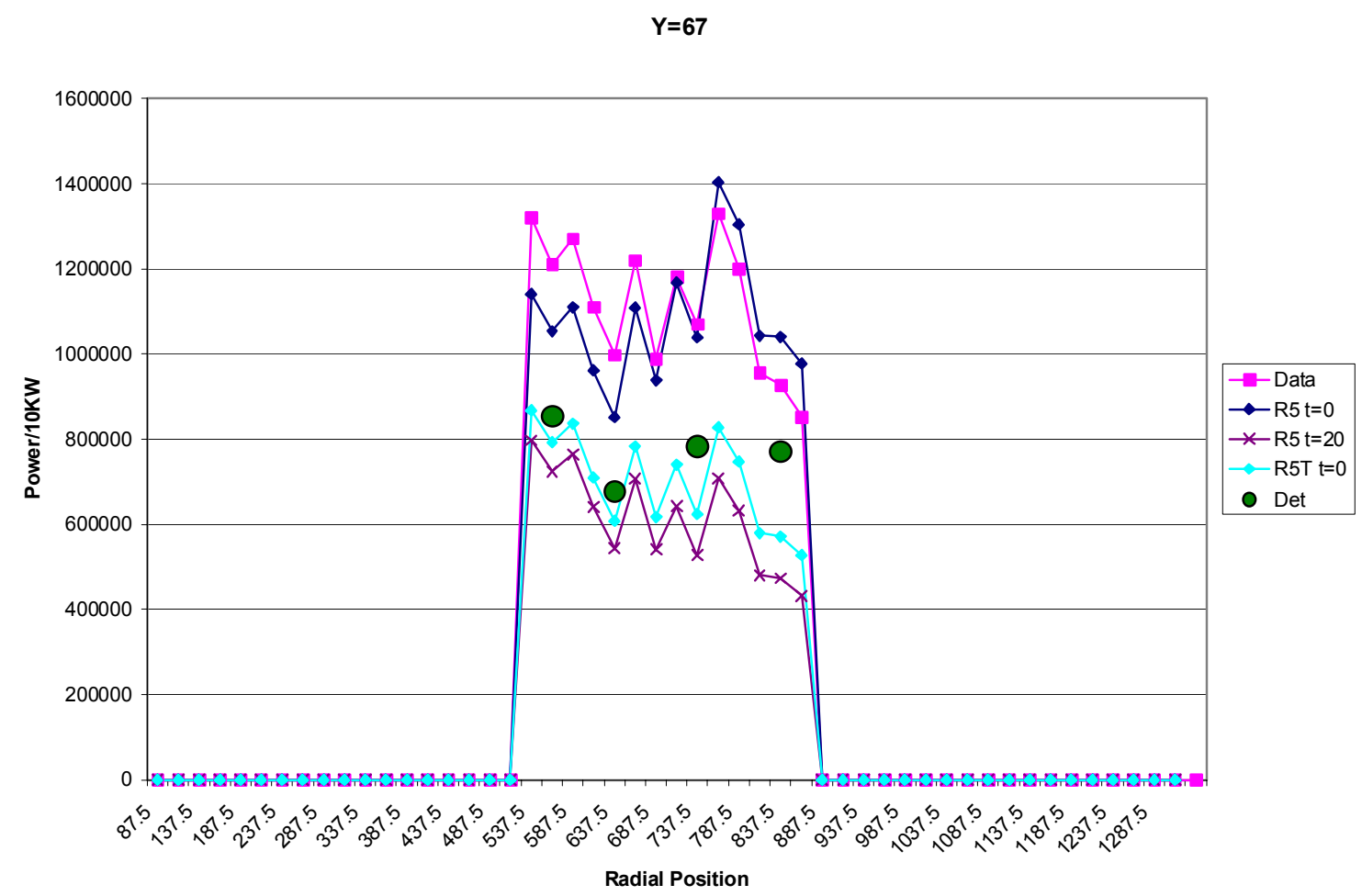

Figure 16. Radial Power Profile at $Y=67$ in 3200 MW core using Nu-Sigf Correction Method. 


\section{References}

1. A. A. Afanasiev, Reconstruction of Power Density Field in RELAP5-3D Code Calculation, Russian Research Center "Kurchatov Institute",. Moscow, 2002.

2. Accident Analysis and its Associated Training Programme for the RBMK 1000 Kursk 1 NPP, International Atomic Energy Agency Technical Report - Draft, Revision 3, Volume II, Section 3.3, Vienna Austria, July 2001. 